\title{
Enucleated L929 mouse fibroblasts support invasion and multiplication of Shigella flexneri $5 a$
}

\section{Yamamoto*, \\ V.C. Coimbra*, \\ K. Okuda and \\ M. Rabinovitch}

\author{
Departamento de Microbiologia, Imunologia e Parasitologia, \\ Universidade Federal de São Paulo, Escola Paulista de Medicina, \\ São Paulo, SP, Brasil
}

\author{
Correspondence \\ M. Rabinovitch \\ Rua Botucatu, 862 \\ 04023-062 São Paulo, SP \\ Brasil \\ Fax: +55-11-5576-4532 \\ E-mail: rabinom@ecb.epm.br \\ M. Rabinovitch dedicates this \\ paper to the memory of \\ Hewson H. Swift (1920-2004) \\ and Daniel C. Mazia (1912-1996). \\ Research supported by $\mathrm{CNPq}$ and \\ FAPESP (No. 2002-04859-1). \\ *These authors contributed \\ equally to this study. \\ $\ldots \ldots \ldots \ldots \ldots \ldots$
}

Received December 20, 2005

Accepted April 5, 2006

\begin{abstract}
Invasive bacteria can induce their own uptake and specify their intracellular localization; hence it is commonly assumed that proximate modulation of host cell transcription is not required for infection. However, bacteria can also modulate, directly or indirectly, the transcription of many host cell genes, whose role in the infection may be difficult to determine by global gene expression. Is the host cell nucleus proximately required for intracellular infection and, if so, for which pathogens and at what stages of infection? Enucleated cells were previously infected with Toxoplasma gondii, Chlamydia psittaci, C. trachomatis, or Rickettsia prowazekii. We enucleated L929 mouse fibroblasts by centrifugation in the presence of cytochalasin B, and compared the infection with Shigella flexneri M90T 5a of nucleated and enucleated cells. Percent infection and bacterial loads were estimated with a gentamicin suppression assay in cultures fixed and stained at different times after infection. Enucleation reduced by about half the percent of infected cells, a finding that may reflect the reduced endocytic ability of L929 cytoplasts. However, average numbers of bacteria and frequency distributions of bacterial numbers per cell at different times were similar in enucleated and nucleated cells. Bacteria with actin-rich tails were detected in both cytoplasts and nucleated cells. Lastly, cytoplasts were similarly infected 2 and $24 \mathrm{~h}$ after enucleation, suggesting that short-lived mRNAs were not involved in the infection. Productive $S$. flexneri infection could thus take place in cells unable to modulate gene transcription, RNA processing, or nucleus-dependent signaling cascades.
\end{abstract}

\section{Introduction}

Paradigmatic bacterial pathogens enter cells by macropinocytosis induced by plasmid- or chromosome-encoded virulence factors, or by phagocytosis initiated by the interaction of microbial surface ligands with
Key words

- Shigella flexneri

- Cell enucleation

- Cytoplasts

- L929 fibroblasts 
or, alternatively, control the maturation, composition and function of pathogen-occupied phagosomes (1-3).

The evidence that non-viral pathogens can control their own uptake, intracellular targeting, access to nutrients, and dissemination in the host while confronting innate and/or acquired host defenses supports the commonly held view that infection can take place in the absence of new host cell transcription, translation and other nucleus-dependent cell functions. Infection of anucleated erythrocytes by bacteria and protozoa has been invoked in support of this hypothesis.

It has also been shown, however, that contact with or uptake of "inert" particles, virulent or nonvirulent microorganisms, their molecular components and/or secreted products can, directly and indirectly, modulate host cell gene expression, particularly, but not exclusively, in professional phagocytes (4). Many, if not most of these responses, common to different microorganisms and viruses, are thought to protect host cells or infected hosts and have been shown to arise by activation of evolutionary conserved stress, alarm and/or innate immunity signaling pathways, whereas others are pathogenspecific (4-6). Host cell patterned responses can trigger the production of pro-inflammatory cytokines, chemokines and antimicrobial effectors, which can further modulate host cell transcription (7). In addition, in the course of infection, changes in the composition of the extra- and intracellular compartments, sensed by the pathogens, also modulate pathogen gene expression $(8,9)$.

Because of the complexity and connectivity of transcriptional and other signaling pathways in eukaryotic cells $(10,11)$, it may be difficult to distinguish between transcriptional responses involved in the protection of infected cells or animal hosts, from those that enhance the intracellular survival, multiplication or dissemination of the pathogens, or may be unrelated to infection $(12,13)$.
Cell enucleation abruptly interrupts ongoing nuclear gene transcription, nuclear mRNA processing and nucleus-dependent signaling cascades. The development in the early 1970s of methods for mass enucleation by centrifugation of cells in monolayers or density gradients in the presence of a cytochalasin was extremely fruitful in broad areas of cell biology (14-16). However, a survey of the literature indicates that, with a few exceptions, in the last two decades the information on the cellular and molecular biology of cytoplasts has lagged behind that available for their nucleated counterparts (Rabinovitch $\mathrm{M}$ and Coimbra VC, unpublished results).

Upon centrifugation, cell nuclei move to the end of thin, long cytoplasmic stalks, which break down generating membranebound "cytoplasts" and "karyoplasts" (17). Cytoplasts were reported to contain all cell organelles known at the time, except for the nucleus and, after a brief chase in cytochalasin-free medium, behaved similarly to nucleated controls for at least several hours with regard to adhesion, spreading, locomotion, shape formation, contact inhibition, or pinosome formation; they were also reported to synthesize proteins, albeit at diminished rates, for about $12 \mathrm{~h}(18-21)$. It is to be expected that the structure, composition, functional preservation, and longevity of cytoplasts will depend on the type and functional state of the donor cells, the enucleation methodology, and the post-enucleation culture conditions $(21,22)$.

We conjectured that earlier reports, modestly recognized in the literature, that cells enucleated microcirurgically or by centrifugation in the presence of cytochalasin B (CB) could be infected with Toxoplasma gondii, Chlamydia psittaci, C. trachomatis, or Rickettsia prowazekii (23-28), have now become particularly relevant. Indeed, given the complexity of host cell responses to intracellular infection, by no means limited to gene transcription and translation, and the 
diversity of cellular phenotypes induced by pathogens $(1-3,29)$, we propose that the requirement for the host cell nucleus should be examined in additional infection models. A useful feature of the enucleation model is that cytoplasts can be challenged with a pathogen at different times after enucleation, thus testing the requirement for short-lived macromolecules, as done in a pioneer study with $T$. gondii (24).

The Gram-negative facultative intracellular enteropathogen Shigella flexneri 5a M90T, an agent of human bacillary dysentery, was chosen for this study because its in vitro infection cycle can be completed in about $5 \mathrm{~h}$, a period largely compatible with the survival of cytoplasts. In addition, extensive high-resolution information on the complex cellular and molecular mechanisms involved in infection of host cells with Shigella sp is available in the literature (e.g., 1,2,30-34).

$\mathrm{HeLa}, \mathrm{Caco} 2$ and other polarized or nonpolarized primary or stable epithelial cell lines have been generally employed for in vitro infection with Shigella. We studied enucleated L929 fibroblast-like cells because L cell cytoplasts have been often used in basic cell biology studies and infected with microbial pathogens (24-27). In addition, L929 cytoplasts survived substantially longer than the enucleated HeLa cells available to us. In our laboratory the $50 \%$ survival of L929 cytoplasts is about $30 \mathrm{~h}$ (Coimbra V and Khusal K, unpublished data). Although L929 fibroblasts can be infected with $S$. flexneri, they do not express cadherins and connexins involved in internalization and direct cell-to-cell transfer of the bacterium $(2,30)$. Thus, it should not be possible to fully reproduce in L929 cells and their cytoplasts the elaborate $S$. flexneri infection phenotype displayed by continuous human epithelial-like cell lines and, more recently, by primary cultures of mouse enterocytes (33).

In the present study, L929 cell monolay- ers were enucleated by centrifugation in the presence of $\mathrm{CB}$, chased in complete medium and infected with $S$. flexneri immediately or $24 \mathrm{~h}$ later. Cultures were fixed at different times after infection and the percent infection and numbers of bacteria were estimated microscopically in stained monolayers. We postulated that infection of cytoplasts with $S$. flexneri could be: 1) absent (an unlikely possibility);2) similar to or lower than that in nucleated cells, or 3), increased in cytoplasts compared to nucleated cells - an outcome expected in cytoplasts derived from cells endowed with functioning nucleus-dependent innate immunity mechanisms.

\section{Material and Methods}

\section{Bacteria, media and growth conditions}

Kanamycin-resistant S. flexneri M90T serotype 5a, and the BS176 strain which was cured of the virulence plasmid pWR100, were originally received by Rosa Maria Silva (Escola Paulista de Medicina, UNIFESP) from Philippe J. Sansonetti (Pasteur Institute, Paris, France). The organisms were grown for $18 \mathrm{~h}$ at $37^{\circ} \mathrm{C}$ in tryptic soy broth (Sigma, St. Louis, MO, USA) enriched with $0.3 \%$ trypsin soy broth yeast extract and supplemented with $30 \mu \mathrm{g} / \mathrm{mL}$ kanamycin. Bacteria recovered by centrifugation at room temperature were resuspended in fresh trypsin soy broth yeast extract with kanamycin and grown at $37^{\circ} \mathrm{C}$ for $3 \mathrm{~h}$ to midlog phase prior to use.

\section{Cells, media and growth conditions}

NCTC clone L929 fibroblasts, originally derived in 1948 from a male C3H-An mouse, were used in this study. The cell's modal chromosome number was reported to be 66 (ATCC on line cell listing). Cells were grown in complete Dulbecco's modified Eagle's medium (cDMEM) with 5\% fetal bovine serum, $2 \mathrm{~g} / \mathrm{L}$ bicarbonate and $15 \mathrm{mM} 3-(\mathrm{N}-$ 
morpholino)propanesulfonic acid. Confluent cultures were trypsinized and $1 \times 10^{5}$ cells seeded for $24 \mathrm{~h}$ in $2-\mathrm{cm}^{2}$ wells, each containing an 8 x 12 mm "mini"-slide which was cut from standard microscope slides.

\section{Enucleation}

L929 cell monolayers on mini-slides were enucleated as described, with minor modifications $(14,15)$. Mini-slides were inserted in 1.5$\mathrm{mL}$ Eppendorf tubes containing, unless otherwise indicated, $1.0 \mathrm{~mL}$ of $2.5 \mu \mathrm{g} / \mathrm{mL} \mathrm{CB}$ in modified cDMEM (with bicarbonate reduced to $0.2 \mathrm{~g} / \mathrm{L}$ ), and the tubes placed in an angle rotor pre-warmed to $36^{\circ} \mathrm{C}$, with the cells facing away from the axis of rotation. Following centrifugation at $10,000 \mathrm{~g}$ for $30 \mathrm{~min}$, minislides were washed once in Hanks' saline, and chased for $2 \mathrm{~h}$ in $\mathrm{cDMEM}$ at $36^{\circ} \mathrm{C}$ in a $5 \%$ $\mathrm{CO}_{2} / 95 \%$ air atmosphere to recover from the effects of CB as judged from the flattening of the cytoplasts over the substrate.

In earlier studies, investigators used relatively high concentration of CB $(10 \mu \mathrm{g} / \mathrm{mL})$ to maximize the yield of cytoplasts (24-28). In the present experiments, with a 4-fold reduction in $\mathrm{CB}$ concentration, 30 to $60 \%$ of the cells were enucleated, allowing the infection of nucleated and enucleated cells to be compared in the same preparations. In certain experiments 5 or $10 \mu \mathrm{g} / \mathrm{mL}$ CB was used for enucleation, respectively yielding about 78 and $97 \%$ cytoplasts.

Following enucleation the total number of nucleated and enucleated cells per mini-slide $\left(96 \mathrm{~mm}^{2}\right)$ estimated from microscope counts were $3.2 \times 10^{4}$ to $7 \times 10^{3}$ cells (mean \pm SEM for 5 experiments). Twenty-four hours after enucleation the number of cytoplasts per area was similar to that in freshly enucleated preparations, while the number of nucleated cells increased as expected.

\section{Infection}

Monolayers on mini-slides containing both nucleated and enucleated L929 cells were infected with $3 \times 10^{6}$ to $1 \times 10^{7} / \mathrm{mL}$ mid-log phase $S$. flexneri 5a M90T in serumfree MEM containing 15 mM HEPES. Bacteria were centrifuged over the cells for 15 min at $1100 \mathrm{~g}, 36^{\circ} \mathrm{C}$, and the plates remained stationary for $45 \mathrm{~min}$ (30). Next, cultures were thoroughly washed and incubated at $36^{\circ} \mathrm{C}$ in a $5 \% \mathrm{CO}_{2} / 95 \%$ air atmosphere in fresh cDMEM containing $50 \mu \mathrm{g} / \mathrm{mL}$ gentamicin. Unless otherwise stated, cultures were fixed in methanol at 1 (zero time), 2 , and $4 \mathrm{~h}$ of infection and stained with Giemsa. Alternatively, cells were fixed in paraformaldehyde for fluorescence microscopy and stained for actin with TRITC-phalloidin (34).

\section{Measurement of the extent of infection}

Since cultures infected after enucleation contained both nucleated and enucleated cells, colony-forming unit counts in cell lysates could not be used to measure infection. Instead, infection was assessed by light microscope counts in monolayers fixed at different times and stained with Giemsa. It may be noted that colony-forming units tend to reflect the infection of a subpopulation of host cells containing high numbers of bacteria. At least 300 nucleated and enucleated cells were scored at $400 \mathrm{X}$ magnification to estimate percent infection. Intracellular bacteria were counted with a $100 \mathrm{X}$ oil immersion objective at $1000 \mathrm{X}$ final magnification in at least 50 nucleated and 50 enucleated cells in each of 2 or 3 replicate slides per point or treatment. Images were also captured with a video camera and viewed at a final magnification of $4000 \mathrm{X}$. Up to $80 \mathrm{bac}$ teria could be reproducibly counted per cell. Higher numbers of bacteria were estimated by counting a part of the cell with the help of a grid and roughly correcting for the total area of the cell. Data are reported as means \pm SEM. Frequency distributions were constructed in classes of 10 bacteria per cell, 
with the frequencies normalized as percent of the total numbers of nucleated or enucleated cells scored. The significance of the differences between averages with time was examined with the help of a Sigma-Stat Package using two-way ANOVA and the Student-Newman-Keuls post-test.

Although cell samples scored for bacterial loads were relatively small (50 nucleated and 50 enucleated cells per slide) they permitted the detection of a time-dependent increase in bacterial loads per cell. The minimum theoretical error (root square of $n$ ) in samples of 50 cells is about $15 \%$ and is reduced to 12.1 and $8 \%$ after pooling counts of 2 or 3 separate mini-slides, respectively.

\section{Results}

Time course of infection of cytoplasts and nucleated 1929 cells with Shigella flexneri

Cytoplasts and nucleated cells infected with S. flexneri M90T 5a were easily recognized in Giemsa-stained preparations. Cytoplasts were generally more flattened and, when infected, they showed more widely scattered bacteria than nucleated cells did (Figure 1). Non-virulent BS176 bacteria did not interact with either nucleated or enucleated L929 cells (data not shown). The results of one of three internally consistent time course experiments are shown in Figures 2 and 3. At all time points the percent infection of enucleated cells was significantly lower than that of nucleated controls $(\mathrm{P}<0.05$; Figure 2A). In contrast, the average numbers of bacteria per cell increased significantly along the course of infection and were similar in cytoplasts and in their nucleated controls (Figure 2B).

In control experiments we infected L929 cells which were either treated with $\mathrm{CB}$ without centrifugation and chased for $2 \mathrm{~h}$ in complete medium or centrifuged in the absence of CB. Infection of these cells did not differ from that of untreated L929 cultures
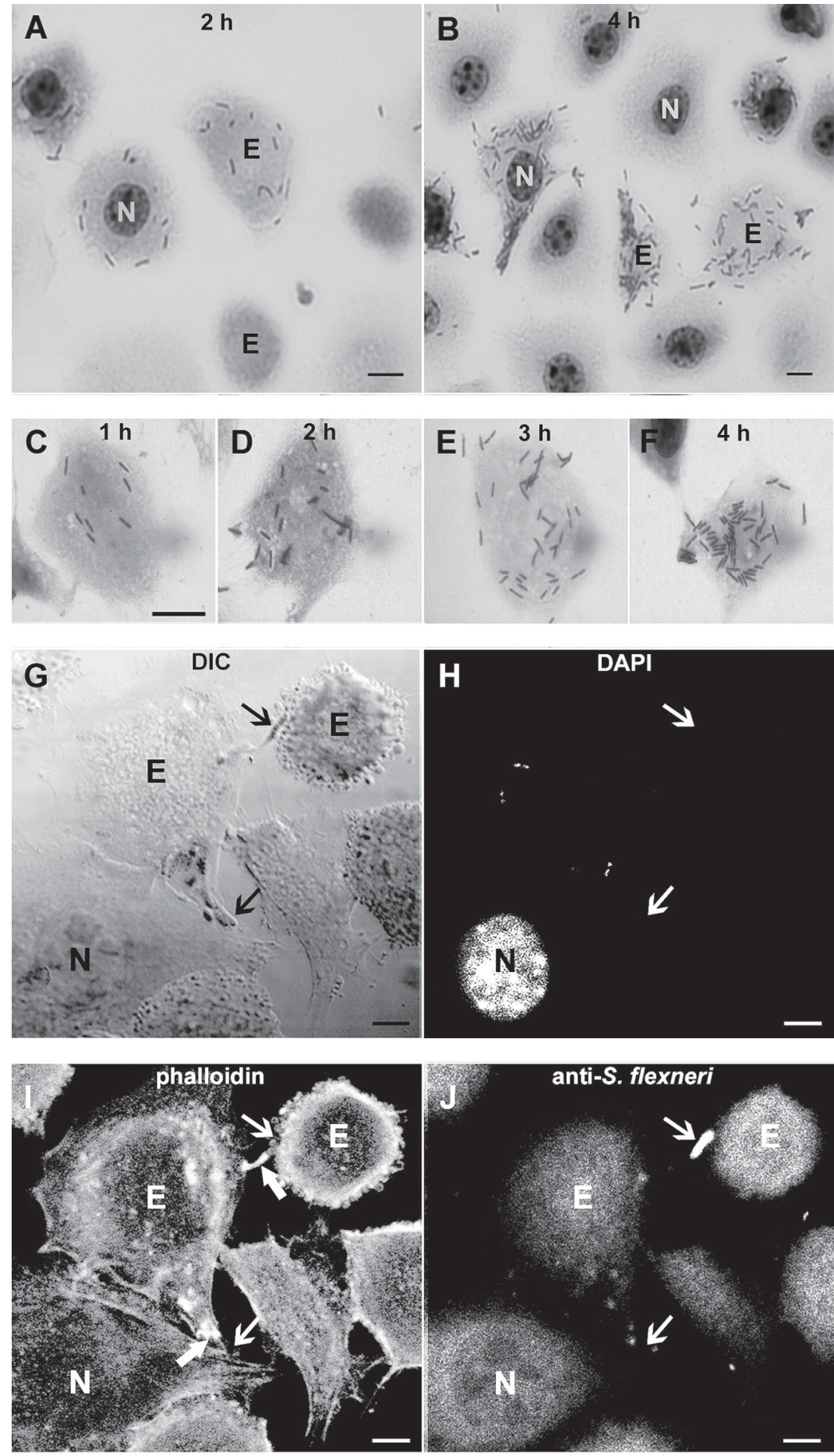

Figure 1. Nucleated (N) and enucleated (E) L929 fibroblasts infected with Shigella flexneri. Cells were enucleated, chased for $2 \mathrm{~h}$ in cDMEM and infected as described in the text. $A$ and $B$, Giemsa-stained cells, 2 or $4 \mathrm{~h}$ of infection. $C$ to $F$, Representative enucleated and infected cells, higher magnification, 1 to $4 \mathrm{~h}$ of infection. $G$ to J, Confocal microscopy; $G$, differential interference contrast (DIC); $H$, nuclei stained with DAPI; I, TRITC-phalloidin stain for F-actin; $J$, anti-S. flexneri. Bacteria (thin arrows) presenting actin tails (thick arrows). Magnification bar $=10 \mu \mathrm{m}$ for all panels. 
Figure 2. Effect of enucleation on the infection of L929 fibroblasts with Shigella flexneri. Percent infection and numbers of bacteria in cytoplasts and nucleated cells are reported as means \pm SEM for 3 experiments as a function of time. Cells were infected as described in the text. In $A$, time was not a statistically significant source of variation in the infection of cytoplasts and nucleated cells. However, at all times the \% infection of cytoplasts was significantly lower than that of nucleated cells $(\mathrm{P}<$ 0.05, two-way ANOVA). In $B$, the time factor was a significant source of variation of bacteria per cell, whereas the presence of the nucleus was not $\left({ }^{*} \mathrm{P}<\right.$ 0.05, two-way ANOVA). (data not shown). These results indicate that the reduced infection of cytoplasts is associated with enucleation itself rather than with exposure to $\mathrm{CB}$ or centrifugation alone. When contact of bacteria and cells was extended from 1 to 2 or $4 \mathrm{~h}$ prior to the addition of
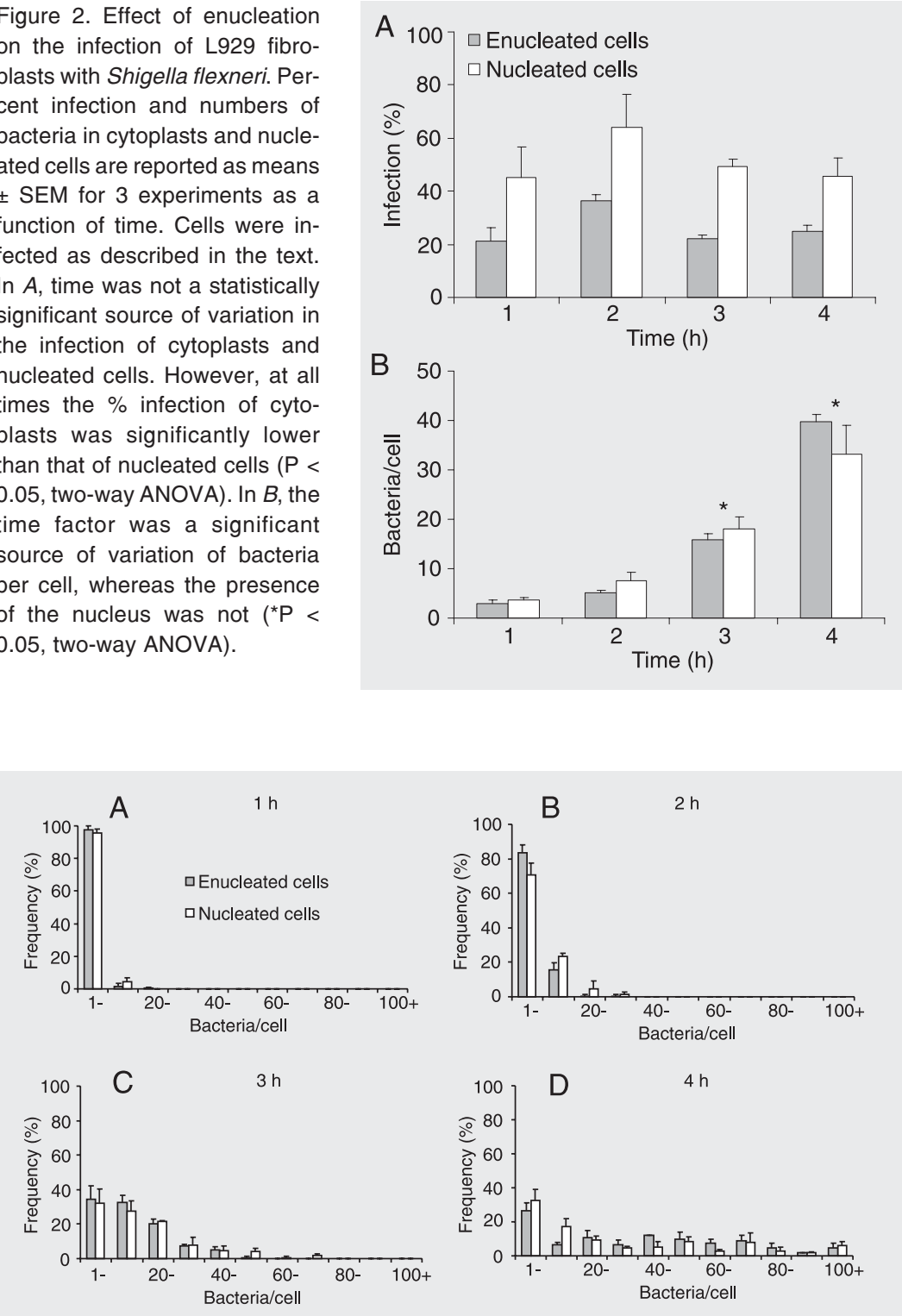

Figure 3. Effect of enucleation on the infection of L929 fibroblasts with Shigella flexneri in terms of frequency distributions of the number of bacteria per cell at intervals of 10 bacteria as percent of the total numbers of cells as a function of time. Cells were infected as described in the text, with cultures fixed at $1,2,3$, and $4 \mathrm{~h}$ of infection, panels A-D respectively (data are reported as means $\pm S E M$, from the same experiment as in Figure 2). Time was a statistically significant source of variation $(P<0.05$, two-way ANOVA), whereas the presence of the nucleus was not. gentamicin, the percent of infected cytoplasts (and of nucleated controls) was substantially increased, indicating that the susceptibility of cytoplasts to Shigella infection was not limited to a defined cell subpopulation (data not shown).

The frequency distributions of bacterial numbers per cell at different times after infection in the same experiment indicate that the course of infection was similar in cytoplasts and in their nucleated controls (Figure 3). As expected, the distributions shifted with time from classes containing few bacteria to those containing higher numbers of organisms. Since, after internalization, cells were incubated with gentamicin, these results support the conclusion that Shigella multiplied within nucleated and enucleated cells. At $4 \mathrm{~h}$ of infection, and increasingly thereafter, some infected nucleated and enucleated cells appeared to be morphologically damaged, with bacteria attached to the cell surfaces (data not shown).

Although quantitative studies were not performed, the reduced numbers of wellpreserved nucleated and enucleated cells at $6 \mathrm{~h}$ agree with information that, depending on the cell type, the number of bacteria per cell or in the cultures falls after 5 or more $h$ of infection. Inspection of the infected monolayers did not reveal morphological features suggestive of cell-to-cell transfer of the bacteria at any time point.

\section{Infection of cytoplasts prepared with CB concentrations that yielded different percentages of enucleation}

In the preceding experiments the concentration of $\mathrm{CB}$ and the centrifugal forces applied were chosen to allow comparison of the infection of nucleated and enucleated cells present in the same preparations. It could be argued that bystander nucleated cells may enhance bacterial multiplication in the cytoplasts. Accordingly, we compared the infection of cytoplasts prepared with 
concentrations of $2.5,5.0$, and $10.0 \mu \mathrm{g} / \mathrm{mL}$ $\mathrm{CB}$, which in a typical experiment yielded 67,78 , and $97 \%$ enucleation, respectively. This experiment demonstrated that a) infection of cytoplasts was unrelated to the proportion of nucleated cells present in the preparations, and b) a 4-fold increase in CB concentration had no effect on percent infection or on the intracellular multiplication of the bacteria (data not shown).

\section{Actin-rich tails in infected cytoplasts}

It was of interest to determine if bacteria would recruit polymerized actin in cytoplasts as they classically do in nucleated cells. Infected preparations, each containing nucleated and enucleated cells, were fixed in paraformaldehyde, stained with DAPI and TRICphalloidin, and examined by confocal microscopy. Bacteria with actin tails were identified in both nucleated and enucleated cells (Figure 1G,H).

\section{Infection of cytoplasts at different times after enucleation}

This experiment was designed to determine if cytoplasts could still be infected $24 \mathrm{~h}$ after enucleation. The results of one of three internally consistent experiments indicate that percent infection, the average numbers of bacteria per cell and the frequency distributions of bacteria per cell did not differ significantly $(\mathrm{P}>0.05)$ between cytoplasts infected 2 or $24 \mathrm{~h}$ after enucleation (Figures 4 and 5).

\section{Discussion}

With the reservation that mechanisms of invasion of L929 fibroblast-like cells with S. flexneri 5a cannot fully reproduce those of polarized epithelial host cells, the facultative $S$. flexneri joins the group of obligatory intracellulars T. gondii, C. psittaci, C. trachomatis, and $R$. prowazekii, previously shown to

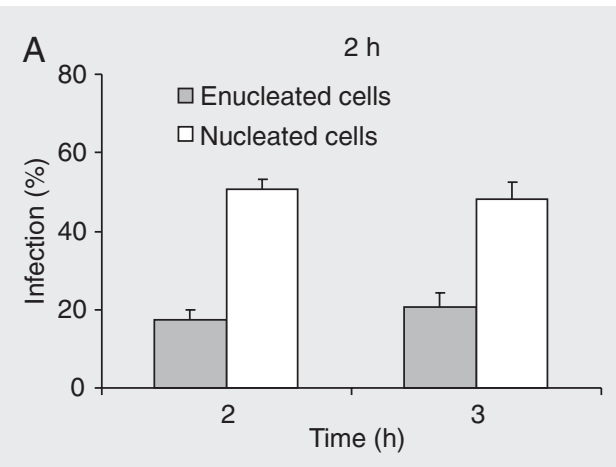

B

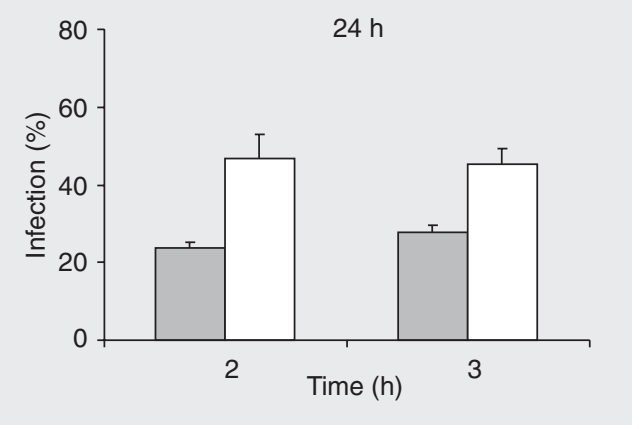

Figure 4. Effect of enucleation on percent infection of nucleated and enucleated cells as a function of cytoplast age. Triplicate cultures were fixed at 2 and $3 \mathrm{~h}$ of infection. Data are reported as means \pm SEM. Cultures infected $2 \mathrm{~h}(\mathrm{~A})$ or $24 \mathrm{~h}(\mathrm{~B})$ after enucleation. Differences between nucleated and enucleated cells attributed to cell age and to duration of infection were not statistically significant. Differences between nucleated and enucleated cells were significant at all time points $(P<0.05$, twoway ANOVA).
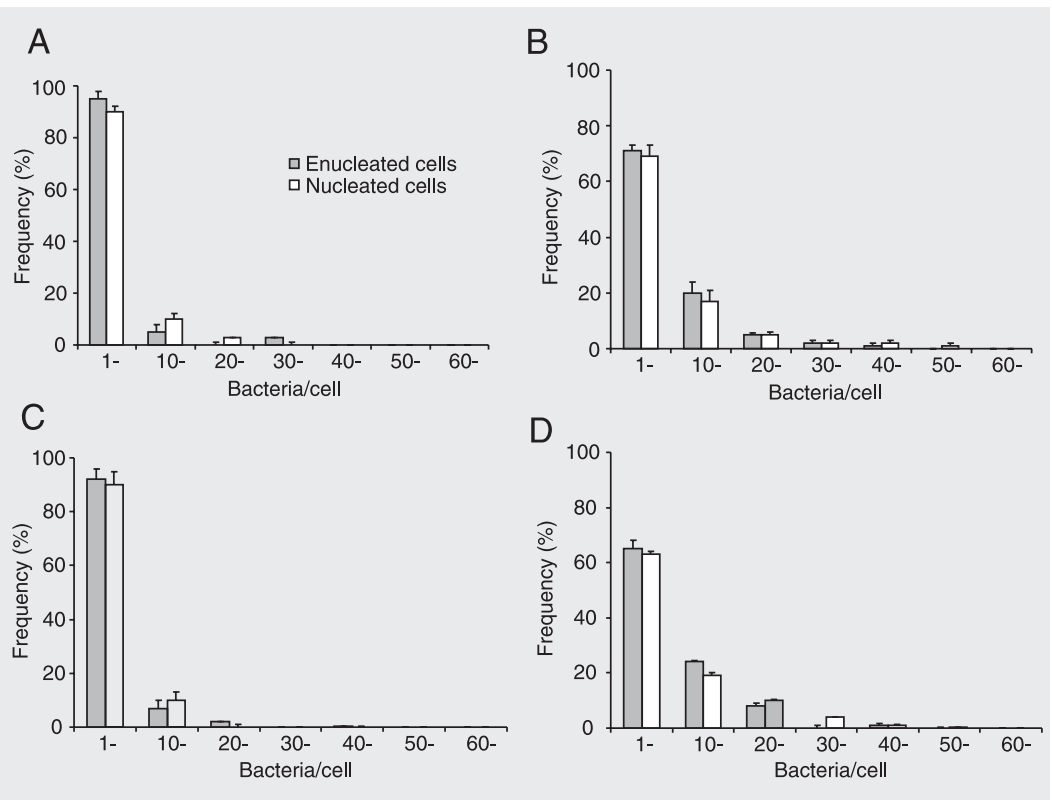

Figure 5. Frequency distributions of bacteria per cell. Same experiment as in Figure 4. Cultures infected $2 \mathrm{~h}$ after enucleation: 2-h infection (A), 3-h infection (B). Cultures infected $24 \mathrm{~h}$ after enucleation: 2-h infection (C), 3-h infection (D). Data are reported as means \pm SEM. Differences between nucleated and enucleated cells attributed to cell age or to the duration of infection were not statistically significant (two-way ANOVA). 
infect L cell-derived cytoplasts (23-28). The implication of this result is that nuclear functions such as modulation of gene transcription, mRNA processing and nucleus-dependent signaling cascades are not proximately required for infection with $S$. flexneri 5a, although, as pointed out in the Introduction, this and other pathogens may extensively modulate host cell transcription in nucleated cells.

Enucleation reduced by half the percent infection of L929 cells with S. flexneri although in infected cytoplasts intracellular multiplication of the bacteria (Figures 2 and 3), assembly of actin-rich tails (Figure 1G,H) and cell destruction were similar to those of nucleated cells examined in the same preparations. Furthermore, the infection of cytoplasts aged $24 \mathrm{~h}$ was equivalent to that of freshly enucleated cells (Figures 4 and 5), suggesting that short-lived mRNAs are not required for the initiation and development of the infection. Non-cytolytic cell-to-cell transfer was not detected, presumably because, as mentioned in the Introduction, L929 cells do not express the adhesion molecules required for the transfer $(30,33)$.

The reasons for the reduced infection of cytoplasts with $S$. flexneri are not yet understood. A less likely hypothesis is that CB could have cellular effects which cannot be reversed in the absence of the nucleus. Cytochalasins have a large number of cellular effects, some of which may not be mediated by reduced actin polymerization. In agreement with the rapid reversibility of the binding of tritiated CB to cells in vitro (35), these effects are generally reversed by a brief chase in drug-free medium. Although a persistent effect of $\mathrm{CB}$ on cytoplasts cannot be excluded, it does not gain support from the lack of concentration dependence and from the persistence of the inhibition of infection in cytoplasts infected $24 \mathrm{~h}$ after enucleation (Figure 5).

A more likely explanation is that L929 cytoplasts may be less active in macropino- cytosis and/or phagocytosis than their nucleated controls. As noted in the Results, the reduced infection may be due to a slower kinetics of the macropinocytic uptake of the bacteria since more cytoplasts were infected when their co-incubation with the bacteria was extended. There are indications of functional and compositional differences between the membrane of cytoplasts and the membrane of nucleated controls. Berke and Fishelson (36) reported that antibody-induced capping was reduced in L929 cytoplasts, and cytoplasts from chick embryo fibroblasts displayed an estimated 35\% reduction in plasma membrane surface with marked enrichment of iodinatable cell surface proteins (37). Further studies on the preservation of different endocytic mechanisms in cytoplasts are clearly needed. It may be of interest that L929 cytoplasts and nucleated cells were similarly infected with Leishmania (L.) amazonensis amastigotes which apparently enter fibroblasts by classic phagocytosis (38, Rabinovitch $\mathrm{M}$ and Coimbra $\mathrm{VC}$, unpublished results).

Rather surprisingly, we did not find reports of the effects of macromolecular synthesis inhibitors such as actinomycin D or cycloheximide on in vitro infection of host cells with S. flexneri 5a. In ongoing experiments we demonstrated that the infection of L929 cells, pretreated for $1 \mathrm{~h}$ with $10 \mu \mathrm{M}$ cycloheximide in complete medium and then infected for $2 \mathrm{~h}$ with $S$. flexneri $90 \mathrm{~T} 5 \mathrm{a}$ in the presence of the drug, was not significantly different from that of untreated controls, as assessed by colony counts of cell lysates (Okuda K and Rabinovitch M, unpublished results). However, since proteins differ in their synthesis and degradation rates, additional experiments should consider both the concentration and the duration of treatment with the inhibitor.

Overall, the present results are compatible with the second outcome postulated in the Introduction, i.e., that infection of cytoplasts could be similar to or lower than that 
of nucleated cells. Since the expression of innate immunity signaling cascades involving TLRs, NODs, NALPs, and other receptors involves transcription factors (4-6), cytoplasts obtained from cells with functional innate microbicidal mechanisms may be more permissive to infection than their nucleated controls, unless additional, as yet uncharacterized, nucleus-independent microbistatic or microbicidal mechanisms operate in such cells. There is apparently no evidence that L929 cells express functional innate immunity mechanisms. It is hoped that the present observations may be extended, with Shigella and other intracellular pathogens, to cytoplasts prepared from host cells able to control at least in part microbial infection (39). It may be of interest that the number of intracellular bacteria later assumed to be symbionts, which colonized Amoeba proteus, was controlled in nucleated cells, but markedly increased in free hand-cut enucleated halves (40).

\section{Acknowledgments}

Help from Drs. Rosa Maria Silva, Renato A. Mortara, Rita C. Ruiz, Mariane Bandeira, and Mr. Rogerio J. Silva Lima, from this University, and comments on an early version of the manuscript by Drs. Silvia C. Alfieri, Maria Julia M. Alves and Octaviano Helene, from the University of São Paulo, are gratefully acknowledged.

\section{References}

1. Knodler LA, Celli J, Finlay BB. Pathogenic trickery: deception of host cell processes. Nat Rev Mol Cell Biol 2001; 2: 578-588.

2. Cossart P, Sansonetti PJ. Bacterial invasion: the paradigms of enteroinvasive pathogens. Science 2004; 304: 242-248.

3. Coombes BK, Valdez Y, Finlay BB. Evasive maneuvers by secreted bacterial proteins to avoid innate immune responses. Curr Biol 2004; 14: R856-R867.

4. Jenner RG, Young RA. Insights into host responses against pathogens from transcriptional profiling. Nat Rev Microbiol 2005; 3: 281294.

5. Kawai T, Akira S. Pathogen recognition with Toll-like receptors. Curr Opin Immunol 2005; 17: 338-344.

6. Chamaillard M, Girardin SE, Viala J, Philpott DJ. Nods, Nalps and Naip: intracellular regulators of bacterial-induced inflammation. Cell Microbiol 2003; 5: 581-592.

7. Ehrt S, Schnappinger D, Bekiranov S, Drenkow J, Shi S, Gingeras $\mathrm{TR}$, et al. Reprogramming of the macrophage transcriptome in response to interferon-gamma and Mycobacterium tuberculosis: signaling roles of nitric oxide synthase-2 and phagocyte oxidase. J Exp Med 2001; 194: 1123-1140.

8. Schnappinger D, Ehrt S, Voskuil MI, Liu Y, Mangan JA, Monahan IM, et al. Transcriptional adaptation of Mycobacterium tuberculosis within macrophages: insights into the phagosomal environment. $J$ Exp Med 2003; 198: 693-704.

9. Lucchini S, Liu H, Jin Q, Hinton JC, Yu J. Transcriptional adaptation of Shigella flexneri during infection of macrophages and epithelial cells: insights into the strategies of a cytosolic bacterial pathogen. Infect Immun 2005; 73: 88-102.

10. Wray GA, Hahn MW, Abouheif E, Balhoff JP, Pizer M, Rockman MV, et al. The evolution of transcriptional regulation in eukaryotes. Mol Biol Evol 2003; 20: 1377-1419.

11. Cusick ME, Klitgord N, Vidal M, Hill DE. Interactome: gateway into systems biology. Hum Mol Genet 2005; 14 (Spec No. 2): R171-
R181.

12. Modlin RL, Bloom BR. Immunology. Chip shots - will functional genomics get functional? Science 2001; 294: 799-801.

13. Portnoy DA. Manipulation of innate immunity by bacterial pathogens. Curr Opin Immunol 2005; 17: 25-28.

14. Prescott DM, Myerson D, Wallace J. Enucleation of mammalian cells with cytochalasin B. Exp Cell Res 1972; 71: 480-485.

15. Wright WE, Hayflick L. Enucleation of cultured human cells. Proc Soc Exp Biol Med 1973; 144: 587-592.

16. Wigler MH, Weinstein IB. A preparative method for obtaining enucleated mammalian cells. Biochem Biophys Res Commun 1975; 63: 669-674.

17. Shay JW, Gershenbaum MR, Porter KR. Enucleation of $\mathrm{CHO}$ cells by means of cytochalasin $B$ and centrifugation: the topography of enucleation. Exp Cell Res 1975; 94: 47-55.

18. Goldman RD, Pollack R, Hopkins NH. Preservation of normal behavior by enucleated cells in culture. Proc Natl Acad Sci U S A 1973; 70: 750-754.

19. Shay JW, Porter KR, Prescott DM. The surface morphology and fine structure of $\mathrm{CHO}$ (Chinese hamster ovary) cells following enucleation. Proc Natl Acad Sci U S A 1974; 71: 3059-3063.

20. Bruno J, Lucas JJ. Polypeptide synthesis in enucleated mouse fibroblasts. Cell Biol Int Rep 1983; 7: 651-659.

21. Goldstein L, Cailleau R, Crocker TT. Nuclear-cytoplasmic relationships in human cells in tissue culture. II. The microscopic behavior of enucleate human cell fragments. Exp Cell Res 1960; 19: 332-342.

22. Degaetano D, Schindler M. Enucleation of normal and transformed cells. J Cell Physiol 1987; 130: 301-309.

23. Crocker TT, Eastwood JM. Subcellular cultivation of a virus: growth of ornithosis virus in nonnucleate cytoplasm. Virology 1963; 19: 2331.

24. Jones TC. Multiplication of toxoplasmas in enucleate fibroblasts. Proc Soc Exp Biol Med 1973; 142: 1268-1271. 
25. Sethi KK, Pelster B, Piekarski G, Brandis H. Multiplication of Toxoplasma gondii in enucleated L cells. Nat New Biol 1973; 243: 255256.

26. Hatch TP. Competition between Chlamydia psittaci and L cells for host isoleucine pools: a limiting factor in chlamydial multiplication. Infect Immun 1975; 12: 211-220.

27. Stork E, Wisseman Jr CL. Growth of Rickettsia prowazeki in enucleated cells. Infect Immun 1976; 13: 1743-1748.

28. Perara E, Yen TS, Ganem D. Growth of Chlamydia trachomatis in enucleated cells. Infect Immun 1990; 58: 3816-3818.

29. Moulder JW. Comparative biology of intracellular parasitism. Microbiol Rev 1985; 49: 298-337.

30. Sansonetti PJ, Mounier J, Prevost MC, Mege RM. Cadherin expression is required for the spread of Shigella flexneri between epithelial cells. Cell 1994; 76: 829-839.

31. Toyotome T, Suzuki T, Kuwae A, Nonaka T, Fukuda H, Imajoh-Ohmi $S$, et al. Shigella protein $\mathrm{IpaH}(9.8)$ is secreted from bacteria within mammalian cells and transported to the nucleus. J Biol Chem 2001; 276: 32071-32079.

32. Pedron T, Thibault C, Sansonetti PJ. The invasive phenotype of Shigella flexneri directs a distinct gene expression pattern in the human intestinal epithelial cell line Caco-2. J Biol Chem 2003; 278: 33878-33886.

33. Athman R, Fernandez MI, Gounon P, Sansonetti P, Louvard D, Philpott D, et al. Shigella flexneri infection is dependent on villin in the mouse intestine and in primary cultures of intestinal epithelial cells. Cell Microbiol 2005; 7: 1109-1116.

34. Mayhew E, Poste G, Cowden M, Tolson N, Maslow D. Cellular binding of 3H-cytochalasin B. J Cell Physiol 1974; 84: 373-382.

35. Gouin E, Gantelet H, Egile C, Lasa I, Ohayon H, Villiers V, et al. A comparative study of the actin-based motilities of the pathogenic bacteria Listeria monocytogenes, Shigella flexneri and Rickettsia conorii. J Cell Sci 1999; 112 (Pt 11): 1697-1708.

36. Berke G, Fishelson Z. Possible role of nucleus-membrane interaction in capping of surface membrane receptors. Proc Natl Acad Sci U S A 1976; 73: 4580-4583.

37. Witt DP, Gordon JA. Most iodinatable fibroblast surface proteins accompany the cytoplast membrane during cytochalasin B-mediated enucleation of chick embryo fibroblasts. J Cell Biol 1982; 94: 557-564.

38. Morehead J, Coppens I, Andrews NW. Opsonization modulates Rac-1 activation during cell entry by Leishmania amazonensis. Infect Immun 2002; 70: 4571-4580.

39. Martinez-Moya M, de Pedro MA, Schwarz H, Garcia-del PF. Inhibition of Salmonella intracellular proliferation by non-phagocytic eucaryotic cells. Res Microbiol 1998; 149: 309-318.

40. Rabinovitch M, Plaut W. Cytoplasmic DNA synthesis in Amoeba proteus. I. On the particulate nature of the DNA-containing elements. J Cell Biol 1962; 15: 525-534. 